\title{
Relation between Pulmonary Gas Exchange and Closing Volume before and after Substantial Weight Loss in Obese Subjects
}

\author{
M. J. B. FĄREBROTHER, G. J. R. McHARDY, J. F. MUNRO
}

British Medical fournal, 1974, 3, 391-393

\section{Summary}

Relations between expiratory reserve volume (ERV), closing volume $(\mathrm{CV})$ as a percentage of vital capacity (CV/VC\%), and pulmonary gas exchange have been investigated in the sitting and supine postures in eight severely obese subjects before and after substantial weight loss. $\mathrm{CV} / \mathrm{VC} \%$ exceeded predicted values but did not change with posture or weight loss; the increase could have been owing to the smoking habits of the subjects. Arterial oxygen pressure $\left(\mathrm{PaO}_{2}\right)$ was significantly less in the supine than in the sitting posture and improved after weight loss in six subjects. The reduction in $\mathrm{PaO}_{2}$ was correlated with the extent to which dependent airways were closed within the range of tidal breathing, shown by increasing negativity of $\mathrm{ERV}-\mathrm{CV}$ as a percentage of VC. A good correlation was also found between $\mathbf{P a O}_{2}$ and ERV, an easier measurement for routine use. Improvement of pulmonary gas exchange occurred only in those patients who lost weight to within $30 \%$ in excess of ideal.

\section{Introduction}

Obese patients often complain of breathlessness and have been shown to have impairment of respiratory function, which may improve with weight reduction. Previous reports have indicated that impairment of gas exchange is associated with changes in the pattern of ventilation due to airway closure but have not fully defined this relation or the nature and extent of improvement with weight loss. We have accordingly studied a group of grossly obese patients before and after substantial weight loss in an attempt to clarify the position.

University Department of Respiratory Diseases, City Hospital, Edinburgh EH10 5SB

M. J. B. FAREBROTHER, M.B., M.R.C.P., Medical Registrar (Present address: Northern Counties Chest Hospital, Newcastle upon Tyne NE4

G. J. R. MCHARDY, B.M., F.R.C.P., Consultant Clinical Respiratory Physiologist

Eastern General Hospital, Edinburgh EH6 7LN

J. F. MUNRO, M.B., F.R.C.P., Consultant Physician

\section{Patients and Methods}

Eight obese patients, admitted for a therapeutic starvation regimen (Munro et al., 1970), were studied (table I). Four were men, and the mean age was 38 years (range 24-56). The mid point of the normal range of "ideal" weight (Metropoli tan Life Insurance Co., 1960) was taken and the percentage in excess of this was calculated. The mean excess was $77 \%$ (range 47-136). All the patients completed the Medical Research Council's questionnaire on respiratory symptoms (1960). Seven were regular smokers; one (case 5) had a morning cough for less than three months in the year and another (case 1) had regular morning sputum. All had a forced expiratory volume in one second $\left(\mathrm{FEV}_{1}\right)$ within two standard deviations of the predicted value Cotes, 1968). After a mean period fasting of 21 weeks (range 8-44) and a mean weight loss of $33.6 \mathrm{~kg}$ (range 18.1-74.8) the mean weight in excess of ideal was $26 \%$ (range 13-46), five subjects having reduced to within $25 \%$ in excess of ideal.

The respiratory measurements were made the day before and about one week after the period of fasting. On each occasion vital capacity (VC) and expiratory reserve volume (ERV) were measured sitting and supine from the spirometric tracings obtained before estimation of closing volume (CV) using argon boluses (Farebrother et al., 1973; Dollfuss et al., 1967). The mean of at least three satisfactory estimates of $\mathrm{CV}$ in each posture was expressed as a percentage of vital capacity (CV/VC\%). The results were compared with predicted values obtained from healthy non-smokers studied in our laboratory, which themselves agree well with the results of others (McCarthy et al., 1972).

Pulmonary gas exchange was studied while the subjects were at rest sitting and after they had been supine for at least 15 minutes. Mixed expired gas and arterial blood were collected over two minutes and analysed for the oxygen and carbon dioxide concentrations in the gas and the arterial oxygen and carbon dioxide pressures. Ideal alveolar $\mathrm{Po}_{2}\left(\mathrm{PAO}_{2}\right)$ was calculated from the alveolar air equation and the alveolararterial oxygen pressure difference $\left(\mathrm{P}(\mathrm{A}-\mathrm{a}) \mathrm{O}_{2}\right)$ was derived. Pulmonary end-capillary oxygen pressure was assumed to equal alveolar oxygen pressure and the oxygen content of end-capillary and arterial blood was derived from the $\mathrm{Po}_{2}$, $\mathrm{pH}$, and haemoglobin concentrations (Kelman and Nunn, 1968).

\section{Results}

The ERV in all subjects was significantly less in the supine than in the sitting posture both before and after weight loss,

TABLE I-Personal Data, Weights, and Periods of Starvation of Eight Obese Patients

\begin{tabular}{|c|c|c|c|c|c|c|c|c|c|c|}
\hline Case No. & $\begin{array}{c}\text { Age } \\
\text { (Years) }\end{array}$ & Sex & $\underset{(\mathrm{cm})}{\text { Height }}$ & $\begin{array}{c}\text { Smoking } \\
\text { Habits } \\
\text { (cigs./ } \\
\text { day) }\end{array}$ & $\begin{array}{c}\text { Ideal } \\
\text { Weight } \\
\text { (kg) }\end{array}$ & $\underset{\substack{\text { Initial } \\
\text { (kg) }}}{\text { (kght }}$ & $\begin{array}{l}\text { Weight } \\
\text { Loss } \\
\text { (kg) }\end{array}$ & $\begin{array}{l}\text { Initial } \\
\text { Weight } \\
\text { (\% of } \\
\text { Ideal) }\end{array}$ & $\begin{array}{l}\text { Final } \\
\text { Weight } \\
\text { (\% of } \\
\text { Ideal) } \\
\end{array}$ & 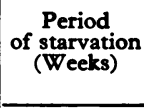 \\
\hline $\begin{array}{l}1 \\
2 \\
3 \\
4 \\
5 \\
6 \\
7 \\
8\end{array}$ & $\begin{array}{l}32 \\
33 \\
35 \\
44 \\
24 \\
38 \\
38 \\
56\end{array}$ & $\begin{array}{l}\text { M. } \\
\text { M. } \\
\text { M. } \\
\text { M. } \\
\text { F. } \\
\text { F. } \\
\text { F. } \\
\text { F. }\end{array}$ & $\begin{array}{l}171 \\
171 \\
178 \\
168 \\
157 \\
164 \\
170 \\
168\end{array}$ & $\begin{array}{r}20 \\
20 \\
5 \\
0 \\
20 \\
12 \\
15 \\
3\end{array}$ & $\begin{array}{l}67.7 \\
70.0 \\
75.8 \\
73.2 \\
57.7 \\
60.5 \\
70.9 \\
73.0\end{array}$ & $\begin{array}{l}118.9 \\
123.5 \\
117.8 \\
107.8 \\
106.5 \\
143.0 \\
132.0 \\
110.3\end{array}$ & $\begin{array}{l}35 \cdot 4 \\
33 \cdot 2 \\
31 \cdot 8 \\
18 \cdot 1 \\
22 \cdot 0 \\
74 \cdot 8 \\
31 \cdot 0 \\
22 \cdot 4\end{array}$ & $\begin{array}{l}176 \\
176 \\
155 \\
147 \\
185 \\
236 \\
186 \\
151\end{array}$ & $\begin{array}{l}123 \\
129 \\
114 \\
123 \\
146 \\
113 \\
143 \\
120\end{array}$ & $\begin{array}{r}16 \\
20 \\
14 \\
8 \\
22 \\
44 \\
27 \\
15\end{array}$ \\
\hline
\end{tabular}


but weight reduction produced a significant increase in the mean value sitting and an increase in the supine values in all but one patient (case 6) though the mean change for the group in this posture was not statistically significant (table II). The mean ( \pm S.E. of mean) of estimates of CV/VC\% sitting and supine for the group before fasting significantly exceeded the mean of the predicted values by $9.3 \pm 2.17 \%$ and $9.0 \pm 2.7 \%$ of VC respectively. After weight loss $\mathrm{CV} / \mathrm{VC} \%$ was not significantly different from the values before fasting in either posture. When CV exceeds ERV airway closure occurs within the range of tidal breathing, and in order to standardize the results the difference between ERV and $\mathrm{CV}$, (ERV - CV, was also expressed as a percentage of VC- $(E R V-C V) / V C \%$. Thus the greater the negative value of (ERV - CV)/VC\% becomes the greater the possible extent of underventilation of dependent lung regions and the greater the likelihood of arterial hypoxaemia. The negative value of this index was significantly greater supine than sitting both before and after weight loss (table III). Before weight loss the value was negative in all patients supine and in all but two (cases 2 and 3) sitting. After weight reduction there was significant improvement in the mean value sitting, the value of the index having become positive in two further patients (cases 1 and 5). In the supine posture the mean improvement after weight loss was not significant, but the value became positive in cases 2 and 3 .

TABLE II-Mean Values ( \pm S.E. of Mean) of Expiratory Reserve Volume $(E R V)$ in Eight Obese Patients in Sitting and Supine Postures before and after Weight Loss.

\begin{tabular}{l|c|c|c}
\hline & ERV (1. B.T.P.S.*) & Significancet \\
\cline { 2 - 3 } & $\begin{array}{c}\text { Before } \\
\text { Weight Loss }\end{array}$ & $\begin{array}{c}\text { After } \\
\text { Weight Loss }\end{array}$ & \\
\hline Sitting & $\begin{array}{c}0.72 \pm 0.11 \\
0.37 \pm 0.07\end{array}$ & $\begin{array}{c}1.19 \pm 0.22 \\
0.58 \pm 0.12\end{array}$ & P $<0.05$ \\
Supine & P $<0.025$ & $P<0.025$ & \\
\hline Significance & P & \\
\hline
\end{tabular}

Body temperature and pressure, saturated.

+ Paired $t$ test (Snedecor and Cochran
N.S. $=$ Not significant $(P>0.05)$.

TABLE III-Mean Values ( \pm S.E. of Mean) of $(E R V-C V) / V C \%$ in Eight Obese Patients Sitting and Supine before and after Weight Loss

\begin{tabular}{|c|c|c|c|}
\hline & \multicolumn{2}{|c|}{$\frac{(\text { ERV-CV })}{V C} \%$} & \multirow{2}{*}{ Significance } \\
\hline & Before & After & \\
\hline $\begin{array}{l}\text { Sitting } \\
\text { Supine }\end{array}$ & $\begin{array}{l}-6.0 \pm 2.9 \\
-15.8 \pm 2.2\end{array}$ & $\begin{array}{l}+3.4 \pm 4.9 \\
-9.5 \pm 4.3\end{array}$ & $\begin{array}{c}\mathrm{P}<0.025 \\
\text { N.S. }\end{array}$ \\
\hline Significance & $P<0.001$ & $P<0.025$ & \\
\hline
\end{tabular}

N.S. $=$ Not significant $(P>0.05)$.

There was no evidence of alveolar hypoventilation; arterial $\mathrm{PCO}_{2}$ did not exceed $46 \mathrm{~mm} \mathrm{Hg}$ in any patient in either posture before or after weight reduction. After weight reduction the arterial $\mathrm{Po}_{2}$ increased in both postures in six patients, but in the other two (cases 5 and 7) it decreased, and the mean changes in $\mathrm{Po}_{2}$ for the group were not significant (table IV). The mean $\mathrm{Po}_{2}$ supine was significantly less than the mean $\mathrm{PO}_{2}$ sitting both before and after weight loss, and it was also significantly less than the mean of the predicted values given by Sorbini et al. (1968) for the supine posture. The mean $\mathrm{Po}_{2}$ sitting, however, did not differ significantly from the mean of the predicted values (Mellemgaard, 1966) for that posture. The relation between arterial hypoxaemia and the degree of underventilation of dependent lung regions is shown in fig. 1 , where arterial $\mathrm{Po}_{2}$ is plotted against (ERV-CV/VC\%. There was also a good relation between arterial $\mathrm{PO}_{2}$ and $\mathrm{ERV}$ itself (fig. 2).
TABLE IV-Mean Values ( \pm S.E. of Mean) of Arterial $\mathrm{PO}_{2}$ in Eight Obese Patients Sitting and Supine before and after Weight Loss

\begin{tabular}{|c|c|c|c|}
\hline & \multicolumn{2}{|c|}{$\mathrm{PaO}_{2}(\mathrm{~mm} \mathrm{Hg})$} & \multirow{2}{*}{ Significance } \\
\hline & Before & After & \\
\hline $\begin{array}{l}\text { Sitting } \\
\text { Supine }\end{array}$ & $\begin{array}{l}84.6 \pm 4.3 \\
77 \cdot 1 \pm 3.5\end{array}$ & $\begin{array}{l}93.9 \pm 5 \cdot 0 \\
81 \cdot 6 \pm 4 \cdot 2\end{array}$ & $\begin{array}{l}\text { N.S. } \\
\text { N.S. }\end{array}$ \\
\hline Significance & $P<0.025$ & $P<0.05$ & \\
\hline
\end{tabular}

* Paired $t$ test.

N.S. $=$ Not significant $(\mathbf{P}>0.05)$.

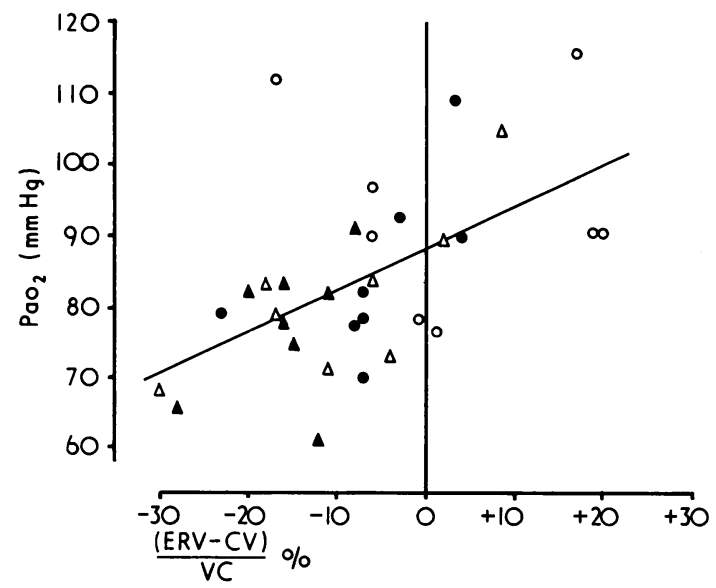

FIG. 1-Relation of Arterial $\mathrm{PO}_{2}$ to (ERV-CV)/VC \% in eight obese subjects. Regression line of closest fit is shown $(y=88.4+0.58 \mathrm{x} ; \mathrm{n}=32 ;$ S.D. from regression \pm 11.2 $\mathrm{mm} \mathbf{H g}$. $=$ Sitting before fasting. $O=$ Sitting after fasting. $\dot{A}=$ Supine before fasting. $\Delta=$ Supine after fasting.

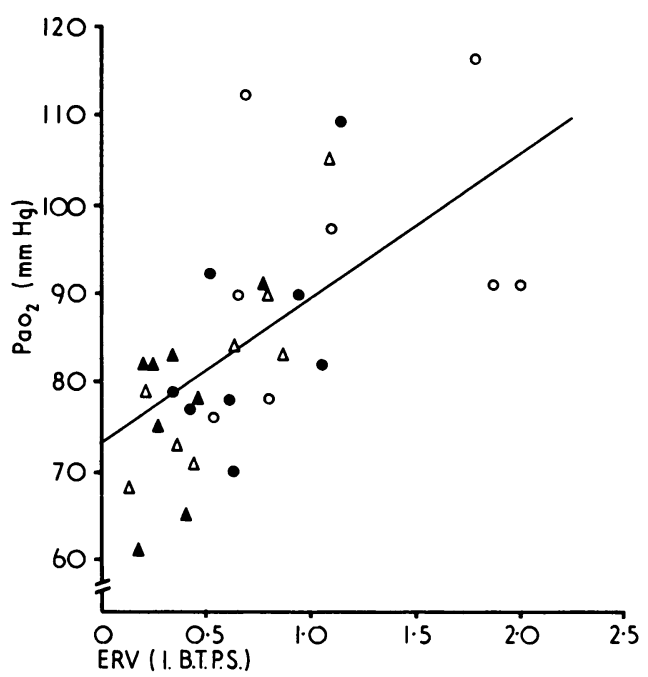

FIG. 2-Relation between arterial $\mathrm{PO}_{2}$ and expiratory reserve volume (ERV) in eight obese subjects. Regres-
sion line of closest fit is shown $(y=73.9+15 \cdot 8$ x; sion line of closest fit is shown $(y=73.9+15.8 \mathrm{x}$;
$\mathrm{n}=32 ; \mathrm{S}$. D. from regression $\pm 10.8 \mathrm{~mm} \mathrm{Hg})$. For $\mathrm{n}=32 ; \mathrm{S}$. D. from reg
key to symbols see fig. 1 .

In analysing the relation between the substantial weight loss achieved by all eight patients and the alterations in arterial $\mathrm{Po}_{2}$ and in the alveolar-arterial $\mathrm{PO}_{2}$ difference in each posture we found a statistically significant $(P<0.05)$ correlation between the final weight and the difference in arterial $\mathrm{Po}_{2}$ in the sitting posture from before to after fasting. When 
the final weight was expressed as a percentage in excess of ideal weight it was significantly correlated with the supine $\mathrm{P}(\mathrm{A}-\mathrm{a}) \mathrm{O}_{\text {: }}$ after fasting, with the difference in $\mathrm{PaO}_{2}$ sitting from before to after fasting and with the difference in $\mathrm{P}(\mathrm{A}-\mathrm{a}) \mathrm{O}_{2}$ supine from before to after fasting. Neither $\mathrm{PaO}_{2}, \mathrm{P}(\mathrm{A}-\mathrm{a}) \mathrm{O}:$ nor the difference due to weight loss in either quantity in either posture was correlated significantly with the change in weight itself, whether expressed in absolute terms or as a change in the percentage of ideal. Improvement of Po: occurred in those patients whose final weight was within $30 \%$ in excess of the ideal.

Because of the alteration in the slope of the oxygen dissociation curve of haemoglobin at varying values of alveolar $\mathrm{Po}_{\text {, }}$, we derived from each value of $\mathrm{P}(\mathrm{A}-\mathrm{a}) \mathrm{O}$. the corresponding end-capillary to arterial oxygen content difference $\left(C\left(c^{1}\right)-a\right)$ $\mathrm{O}_{2}$ ). This difference may be a better index of blood flow through unventilated or underventilated lung regions when comparisons are made under conditions of differing alveolar ventilation and thus of altered alveolar $\mathrm{Po}_{2 .}$. The change in content difference from before to after fasting was found to be significantly correlated with final weight as a percentage of ideal in both postures, and the regression of the change in $\left.\mathrm{C}\left(\mathrm{c}^{1}\right)-\mathrm{a}\right) \mathrm{O}^{2}$ in either posture on final weight as a percentage of ideal cuts the horizontal axis at $33 \%$ in excess of ideal weight (fig. 3). This again indicates that reduction of the "shunt effect" of poorly ventilated areas of lung is less likely to occur above this level.

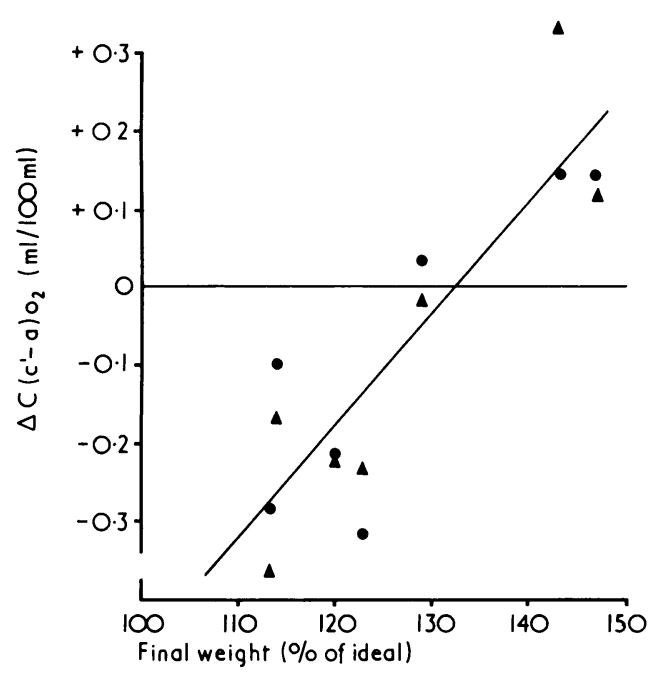

FIG. 3-Relation between change of $\mathrm{C}\left(c^{1}-a\right) \mathrm{O}_{2}$ from before to after weight loss and final weight as percentage of ideal in seven obese subjects. Regression line of closest fit is shown $(y=0.014 \times-1.87 ; n=14 ;$ S.D. closest fit is shown $(\mathrm{y}=0.014 \mathrm{x}-1 \cdot 87 ; \mathrm{n}=14 ;$ S.D.
from regression $\pm 0.11 \mathrm{ml} / 100 \mathrm{ml})$. $\Delta=$ Supine.

\section{Discussion}

In addition to the Pickwickian syndrome of hypoventilation, polycythaemia, and right heart failure (Sieker et al., 1955; Burwell et al., 1956) obesity has previously been associated with impairment of pulmonary oxygen transfer (Said, 1960; Barrera et al., 1967), reduction in expiratory reserve volume (Bedell et al., 1952; Tucker and Sieker, 1960), and underventilation of the lower zones of the lung (Holley et al., 1967; Couture et al., 1970). Our results confirm that ERV is significantly reduced in the grossly obese, especially in the supine posture. This could be due to increased chest wall elastic recoil (Cullen and Formel, 1962), analogous to the effect of strapping the chest and abdomen. As closing volume is reduced by strapping (Manresa, F. and McHardy, G. J. R., unpublished observations) this mechanism could not account for the observed increase in closing volume. McCarthy et al. (1972) have found that smoking may be associated with increases in CV, and this may account for the findings in the present study. Whatever the cause, the decreased ERV and increased CV combine to produce underventilation of dependent lung regions during resting tidal breathing, especially when the patient is supine.

The extent of airway closure within the range of tidal breathing has been related to arterial $\mathrm{PO}_{2}$ in subjects of near normal weight by Craig et al. (1971). The present study showed a close correlation between arterial $\mathrm{Po}_{2}$ and the extent of airway closure within the range of tidal breathing putting the causal relation in obese subjects, first recognized by Holley et al. (1967), on a firm quantitative basis. Increased depth of breathing would improve the arterial $\mathrm{Po}_{2}$ in this situation (Said, 1960). George and Weill (1971) have also showed by fluorodensitometry that decreased lower zone ventilation is found in obesity and is reversed by deep breathing. That ERV alone is directly related to $\mathrm{PaO}_{2}$ both sitting and supine would suggest that reductions of ERV are largely responsible for bringing tidal breathing into the range of lung volume in which airway closure occurs. While estimation of $\mathrm{CV}$ provides an explanation of the mechanism, it is clearly much easier in practice to measure ERV, especially as it correlates better than (ERV-CV)/VC\% with $\mathrm{PaO}_{2}$ presumably because the latter index introduces errors from three estimates rather than one.

We were surprised that improvement of gas exchange after substantial weight loss was limited and failed to occur unless there was reduction to within about $30 \%$ in excess of ideal weight. This suggests that a relatively low weight threshold may have to be passed. Thus for the severely obese subject to achieve respiratory improvement by weight loss it seems to be not that "little is good, but more is better," but rather that "little is no good, and much is essential."

We thank Miss Sylvia Merchant and the technical staff of the respiratory laboratory, City Hospital, Edinburgh, for skilled technical help; Dr. J. F. Munro's staff at Edenhall Hospital, Musselburgh, Midlothian; Drs. Catherine Campbell, Elizabeth Hamilton, Anne Needle, and H. E. Martin for their help with the arrangements and for administering the M.R.C. questionnaires; and the patients for their cheerful co-operation.

\section{References}

Barrera, F., Reidenberg, M. M., and Winters, W. L. (1967). American Fournal of the Medical Sciences, 254, 785.

Bedell, G. N., Wilson, W. R., and Seebohm, P. M. (1958). Fournal of Clinical Investigation, 37, 1049.

Burwell, C. S., et al. (1956). American fournal of Medicine, 21, 811.

Cotes, J. E. (1968). Lung Function, 2nd edn. Oxford and Edinburgh, Blackwell Scientific Publications.

Couture, J, et al. (1970). Federation Proceedings, 29, 269.

Craig, D. B., et al. (1971). Fournal of Applied Physiology, 31, 717.

Cullen, T. H., and Formel, P. F. (1962). American fournal of Medicine, 32, 525.

Dollfuss, R. E., Milic-Emili, J., and Bates, D. V. (1967). Respiration Physio$\log y, 2,234$

Farebrother, M. J. B., et al. (1973). Clinical Science, 44, 181

George, R. B., and Weill, H. (1971). Fournal of the American Medical Association, 217, 171 .

Holley, H. S., et al. (1967). Fournal of Clinical Investigation, 46, 475

Kelman, G. R., and Nunn, J. F. (1968). Computer produced Physiological Tables. London, Butterworths.

McCarthy, D. S., et al. (1972). American fournal of Medicine, 52, 747

Medical Research Council. (1960). British Medical fournal, 2, 1665.

Mellemgaard, K. (1966). Acta Physiologica Scandinavica, 67, 10.

Munro, J. F., et al. (1970). British Medical fournal, 4, 712.

Metropolitan Life Insurance Company. (1960). Overweight; its Prevention and Significance. New York, M.L.I.

Said, S. I. (1960). Annals of Internal Medicine, 53, 1121.

Sieker, H. O., et al. (1955). Fournal of Clinical Investigation, 34, 916.

Snedecor, G. W., and Cochran, W. G. (1967). Statistical Methods, 6th edn. Ames, Iowa, Iowa State University Press.

Ames, lowa, lowa State University Press.
Sorbini, C. A., et al. (1968). Respiration, 25, 3. Tucker, D. H., and Sieker, H. O. (1960). American Review of Respiratory
Disease, 82, 787 . 